
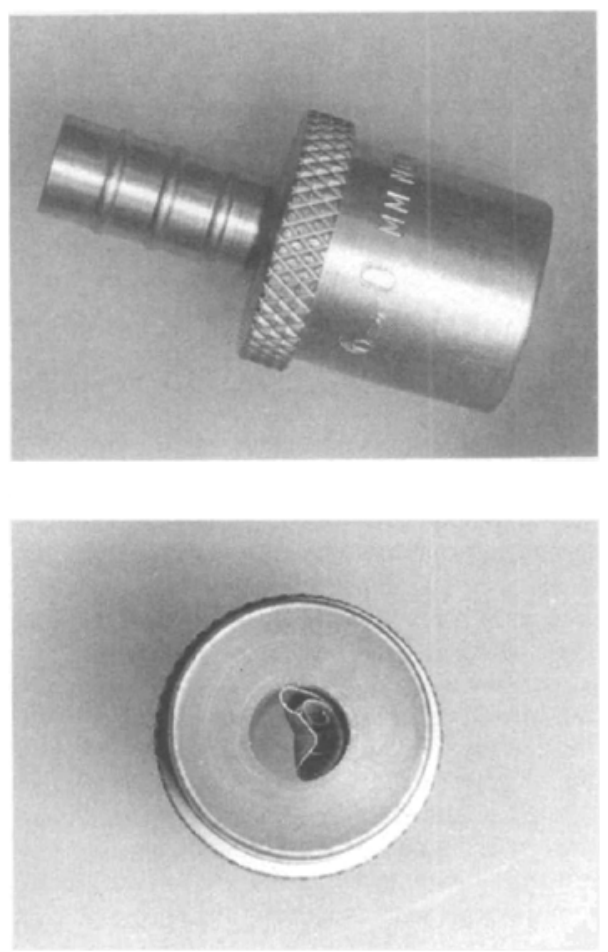

Upon completion of a particularly difficult case involving nasal re-intubation for control of postoperative haemorrhage following maxillofacial surgery with wire jaw closure, airway maintenance was a major concern. The nasotracheal tube was left in position, sutured to the nasal septum, with the intent of connecting it to a T-piece for administration of humidified oxygen. For positional convenience the acute angled \#6 connector was removed for replacement with a straight connector. The one selected from a box of new connectors is illustrated.

Possibly because of the continuing difficulties with the case, and certainly not because of any routine habit of checking connectors, I checked this one carefully before use, to find the defect shown. An internal metallic stamping defect has left a flap-like semi-attached piece of debris which occludes the lumen by approximately 40 per cent. Though the metallic flap is not loose, it could well become dislodged and aspirated. Further, in an angled connector, if such a flap had pointed towards the narrow tube end, the defect might well have escaped casual inspection, hidden by the bend in the connector.

The manufacturer has been consulted and some reassurance has been given that each connector is carefully inspected before issue. Clearly, this is not entirely effective. It is now my practice to check all connectors routinely before use.

W. Douglas Lahay, M.D., F.R.C.P.(C) Department of Anaesthesia, Health Sciences Centre Hospital, U.B.C.

\section{Postoperative OXYGEN}

DeAr Sir,

RE: J.R. Rigg: Pulmonary Atelactasis After Anaesthesia, Pathophysiology and Management, Canadian Anaesthetists' Society Journal 28: 305 (July 1981).

I find Dr. Rigg's simplistic approach to this topic informative and well presented. However, I would like to comment on the part of the article concerning oxygen therapy. He wrote: "Although hypoxaemia has been shown to occur in all patients post-operatively ..., these observations have led to the routine use of oxygen after general anaesthesia, but the wisdom of this practice may be questioned for several reasons." Studies done on healthy subjects by Knill, et $a l^{1-3}$ may prove that routine use of oxygen after general anaesthesia is a wise practice after all. These studies demonstrated that subanaesthetic levels (0.1 M.A.C.) of halothane ${ }^{1,2}$ and enflurane ${ }^{3}$ can cause marked depression of hypoxic response of peripheral chemoreceptors. These alveolar anaesthetic levels are not uncommon in the Post-Anaesthetic Recovery Room in patients. who have received the above inhalation agents. Perhaps supplemental oxygen in the Recovery Room in the form of 28 per cent oxygen via venturi-type mask is not so irrational even in patients with chronic lung disease.

Peter B.K. Chan, M.B., B.S., F.R.C.P.(C), Department of Anaesthesia,

St. Joseph's Hospital,

Hamilton, Ontario.

\section{REFERENCES}

1. KNiLl, R.L. \& GeLB, A.W. Ventilatory responses to hypoxia, hypercarbia and doxapram. Anesthesiology 49: 244 (1978).

2. GELB, A.W. \& KNILL, R.L. Subanaesthetic halothane: Its effect on regulation of ventilation and relevance to the recovery room. Can. Anaesth. Soc. J. 25: 488 (1978).

3. Knill, R.L., Manninen, P.H. \& Clement, J.L. Ventilation and chemorefiexes during enflurane sedation and anaesthesia in man. Can. Anaesth. Soc. J. 26: 353 ( 1979). 